\title{
Erratum
}

\section{Partition coefficients for olivine-melt and orthopyroxene-melt systems}

\section{Paul Beattie $^{1}$, Clifford Ford ${ }^{2}$, and Douglas Russell ${ }^{3}$}

${ }^{1}$ Department of Earth Sciences, University of Cambridge, Cambridge CB2 3EQ, UK

${ }^{2}$ Grant Institute of Geology, University of Edinburgh, Edinburgh EH9 3JW, UK

${ }^{3}$ Systems Department, Standard Life Assurance Company, George Street, Edinburgh EH2 2XZ, UK

Contrib Mineral Petrol (1991) 109:212-224

We have become aware of an error in our recent paper. The empirical coefficients calculated for Fe partition coefficients between olivine or orthopyroxene and melts in Tables 1 and 2 are incorrect and should read as follows:

Table 1. Olivine/melt partition coefficients

$\begin{array}{llllll}\text { Element } & \text { A } & \text { B } & \text { n } & \text { r } & \sigma \\ \text { Fe } & 0.299 & 0.027 & 898 & 0.93 & 0.132\end{array}$

Table 2. Orthopyroxene/melt partition coefficients

$\begin{array}{llllll}\text { Element } & \mathrm{A} & \mathrm{B} & \mathrm{n} & \mathrm{r} & \sigma \\ \mathrm{Fe} & 0.264 & 0.129 & 146 & 0.91 & 0.264\end{array}$

This error does not affect any of the other data or the conclusions of this paper. 